\title{
Uma amadora, do verbo amar... Paixão!
}

\author{
Tatiana Belinky \\ É escritora, tradutora, adaptadora de livros infantis. \\ Esposa de Júlio Gouveia, com quem dividiu a responsabilidade do trabalho \\ da primeira adaptação da obra de Monteiro Lobato para a televisão. \\ E-mail: tatianabelinky@globo.com
}

Grande parte da minha vida foi junto ao teatro. Eu sempre gostei - desde os 4 anos, quando fiz o papel de mosca numa peça. Meus pais eram russos, loucos por teatro. Casei com Júlio Gouveia em 1940, um brasileiro, médico psiquiatra e educador nato. Por isso, nós pudemos fazer um trabalho educacional. Não foi uma brincadeira qualquer. Não, era uma coisa muito séria. Eu ia ao teatro desde pequena com meus pais e depois continuei. Quando tinha 16 anos, fazíamos teatro no quintal da minha casa e um dos atores participantes era Paulo Autran, que tinha 14 anos e era ginasiano, irmão de uma colega de classe, Gilberta Autran. Brincávamos de teatro.

Agora, escrever para teatro, como escrevo, começou com meu marido, Júlio Gouveia, ao fazer teatro para crianças pela Prefeitura de São Paulo, em 1948. Foram quase três anos, todos os fins de semana. Depois veio a televisão e, entre os anos de 1952 e 1966, fomos convidados a fazer teatro infantil. Nossa idéia era promover a leitura por meio de teleteatro baseado em livros, em literatura brasileira e estrangeira, qualquer boa literatura - eu como roteirista e ele como diretor, produtor e apresentador. Escrevi muitas peças, muitas mesmo. E, assim, acompanhamos o teatro, fizemos teatro, assistimos a teatro.

Naquela época, trabalhar para crianças era tarefa difícil, mas também prazerosa. O teatro para crianças quase não existia. Havia muito preconceito, pois o teatro não era considerado uma atividade séria pelos mais ricos. Gente pobre nem o conhecia. E o que mais fazia sucesso era o teatro de revista, teatro de grandes produções, tudo muito festivo. É claro que, para os ricos, existia o teatro de fora... vinha o que havia de melhor, as grandes companhias, especialmente no tempo de guerra. Todo mundo vinha para cá em turnês: a Comedie Française e muitas outras. Havia teatro do bom para quem tinha dinheiro. Agora, teatro brasileiro era um bom teatro, como o teatro do Procópio Ferreira, o de Dulcina e Odilon e diversos outros. Havia teatro brasileiro para adultos.

Os atores de teatro não eram considerados profissionais, não tinham nem carteira de trabalho. Até muitos anos depois, para conseguir uma aposentado- 
ria, um astro como Procópio Ferreira levava a vida inteira até conseguir - se é que conseguia. Por sua vez, o grande teatro europeu, americano, era muito respeitado e muito bem pago. $\mathrm{O}$ teatro brasileiro que começou a ser respeitado foi o Teatro Brasileiro de Comédia, o TBC, quando foi fundado pelo italiano Ciccilo Matarazzo, e aí começaram a fazer teatro para valer com diretores italianos, importados. Os atores eram brasileiros, mas os diretores vinham de fora porque nem havia quem fizesse isso, daquele jeito, à moda européia.

Meu trabalho era com a literatura - peças extraídas do folclore, da Bíblia, da literatura mundial. Boa literatura, sempre bem escolhida, pois eu tinha acesso aos originais em várias línguas. Fiz peças adaptadas de contos clássicos e até de romances. Eu me saí bem escrevendo peças porque, desde criança, via teatro e lia teatro. Sabia como escrever e peguei um traquejo "brabo". Até hoje, volta e meia aparecem peças minhas para crianças, pelo Brasil. Eu escrevo livros pequenos de tamanho, mas não são livrinhos, e sim boas histórias.

\section{TUDO É POLÍTICO}

Na televisão, o trabalho dos autores era fiscalizado de perto. Havia uma censura moral e política, pois todo trabalho e tudo que você faz na vida têm um fundo político. Pode não ser assim descaradamente, de forma aberta, mas, no fim, todos os textos têm um fundo político. E tudo é educação. Somos todos educadores bons ou maus. O exemplo, o discurso, a briga, tudo é educação. Pode ser péssima educação. Pode ser educação informativa ou formativa, ou deformativa ou conformativa, mas é tudo educação. Tudo leva alguma mensagem. E é preciso entender, interpretar. Qualquer conto de fadas é político. Há sempre os oprimidos e os opressores, a luta dos pobres contra os ricos - é político.

Os fiscais tinham, porém, muita confiança em nosso trabalho. A tal ponto que o juiz de menores, que fiscalizava a televisão, um belo dia disse para o Júlio, que era o diretor: "Você fica encarregado dessa parte. Eu não preciso nem ver". Ele foi o representante do juiz de menores em suas próprias peças. Até mesmo os meus eram textos mandados a Brasília para a censura central, meus e de todo mundo. Tudo era censurado... não existia um fiscal que vinha e olhava. Mas, para a produção teatral ou qualquer uma, havia grande censura e no fim de algum tempo eles tinham que carimbar, liberar. Eles já carimbavam os meus textos sem ver, mas porque eram educativos e não abertamente políticos.

Nossa proposta era passar a mensagem implicitamente e não determinar: "Isso pode. Isso não pode"; "Isso é bom. Isso é mau"; nada de especificamente didático, e sim ético e estético. Odeio isso desde pequena. Não tem nada de me dizer o que eu tenho que compreender. A minha cabeça serve para eu entender o que eu quiser entender, ou o que puder entender. Então, não havia "dedo em riste". Contava-se uma boa história e as crianças de qualquer idade tiravam as suas próprias conclusões, e o nosso cuidado era em escolher histórias que levassem a isso, à boa literatura, não à literatura vagabunda. Teatro é teatro. Para crianças, tem de ter começo, meio e fim, quer dizer, apresenta- 
ção, nó dramático, conflito e solução. A criança precisa se identificar com um personagem. Às vezes, com o vilão, com todo o direito, conforme sua própria interpretação.

Quando fazíamos teatro para a prefeitura, a peça estreava primeiro no Municipal. Era um sucesso, lotava-se o teatro, pois, além de ser de graça, levavam as crianças de ônibus. A própria prefeitura mandava buscá-las em parques infantis. Mas não existia uma invasão geral, havia ingresso, muita ordem e muito respeito. Não se via bagunça. Não era programa de auditório.

Nossa primeira peça foi Peter Pan. Há a fada, os meninos e, enfim, o próprio Peter Pan, que não queria crescer, e também o Capitão Gancho como vilão. $\mathrm{O}$ público adorava e, em geral, torcia pelo Peter Pan e contra o Capitão Gancho. No entanto, algumas vezes, em um teatro da periferia, o público torcia pelo Capitão Gancho. Está aí a política. Mas ninguém falava em política, nem se dizia: "Tem que entender isso. Tem que entender aquilo". "Isso é bom. Isso é mau".

Algumas peças, alguns espetáculos tinham a participação de crianças e a escolha ficava a cargo do próprio Júlio, que dizia quem podia e como podia. Não havia estrelismo. Criança que participasse deveria ter boas notas na escola, tinha que se comportar bem. Não existiam predileções ou preferências. Nada disso. Ele era educador, psiquiatra, psicólogo. Não brincava em serviço.

\section{A PROGRAMAÇÃO INFANTIL}

Engraçado... tínhamos uma posição sui generis, tanto no palco como na televisão. Trabalhávamos sem contrato. O Júlio não aceitava contrato, porque ele sabia o que queria e o que eu queria. Ele disse certa vez: "Nós vamos fazer o que achamos certo, do jeito que achamos certo e não queremos interferência de espécie nenhuma. Não quero contrato. O dia que eu achar que estão se intrometendo, no dia seguinte, eu não venho". E trabalhamos sem contrato, com carta-branca. Ninguém "metia o bedelho". Nem patrocinador, nem a emissora, ninguém. Fazíamos do nosso jeito e funcionou por quase quatorze anos, sem interrupção. Nossos trabalhos estavam entre os carros-chefes da emissora, da editora, e davam ibopes altíssimos.

Nosso primeiro grande seriado foi o Sítio do Pica-pau Amarelo ${ }^{1}$. Houve centenas de capítulos. Mas eu me diverti. Era um trabalho gostoso e muito sério. Havia também o Teatro da Juventude, que era um teatrão aos domingos, com duração de uma hora e meia ou mais. Em cada domingo contava-se uma história completa diferente e o único que aparecia sempre era o Júlio, o apresentador. Ele tirava o livro da estante e começava a ler. Ao final dizia: "Entrou por uma porta, saiu por outra, quem quiser que conte outra”. Além desse programa, havia um teatro, chamado hoje de seriado ou minissérie, que era um romance em capítulos, cinqüenta ou sessenta no total. No fim de cada capítulo, o Júlio começava a ler o seguinte, porém interrompia e dizia: "Bem, mas isso é uma outra história que fica para uma outra vez".
1. Foram 320 episódios semanais, levados ao ar pela TV Tupi, às $19 \mathrm{~h} 30$, ao vivo e não gravados, sendo o primeiro episódio "A Pílula Falante", que estreou em 3 de junho de 1952. 
comunicação \& educação • Ano X * Número 2 - maio/ago 2005

\section{CONTEÚDO E COMÉRCIO}

Fazíamos um programa cultural, educacional, formativo, estético e ético numa TV comercial, que era a Tupi, e o Júlio não permitia nenhum comercial nem merchandising. Não interrompia o texto com comercial. O patrocinador só aparecia no começo dizendo, por exemplo: "O chocolate Lacta apresenta..."; "O Biotônico Fontoura apresenta...” e no fim, "O chocolate Lacta apresentou...”; “O Biotônico Fontoura apresentou...”, mas no meio, nada. Além disso, o Júlio era quem escolhia o patrocinador. Não aceitávamos qualquer um. O contrato era entre a emissora e o patrocinador, mas para nosso programa. Então, um produto com o qual não concordássemos, que não fosse bom para criança, não era aceito. Assim, às vezes, o programa ficava no ar sem patrocinador por várias semanas, até aceitarmos outro.

Éramos independentes. Fazíamos aquilo porque queríamos, porque tinha boa qualidade, modéstia à parte. Nossas primeiras experiências na televisão fizeram enorme sucesso. Começaram a "chover" ofertas de patrocínio, mas não era tão comercial quanto agora.

Nós não possuíamos recursos técnicos naquele tempo, era tudo ao vivo. Como não havia gravação, executava-se na hora, com três grandes câmeras "jurássicas” e uma mesa de som manual. Era uma ginástica danada para conseguir efeitos especiais quando se precisava, por causa da magia, fantasia, por ser coisa para criança. Havia apenas cabeça, criatividade e coragem. Coragem para enfrentar, ao vivo, complicações que esperávamos que fossem solucionadas. Havia um ensaio - chamado ensaio de câmera - antes de se entrar no ar e, depois, era o que Deus quisesse. E Deus quis, sempre ajudou.

Nosso teatro, aos domingos de manhã, no começo se chamava Era uma vez, e fazia grande sucesso. Aí chegaram algumas reclamações dos pais das crianças. E sabe do que eles reclamavam? Que as crianças não queriam ir à missa. Diante disso, o programa passou para domingo à tarde e mudou de nome, Teatro da Juventude.

Uma vez, quando estávamos no primeiro ano do Sítio do Pica-pau Amarelo, o Júlio resolveu fazer uma pesquisa e solicitou, pela televisão, que as professoras da rede escolar pedissem um trabalho às crianças sobre o Sítio do Pica-pau Amarelo. Não era concurso, não havia prêmio, nada disso. Era só uma pesquisa. Para as crianças menorzinhas, de primeira e segunda série, foi pedido um desenho, e para as crianças da terceira e quarta, uma redação sobre o Sítio. Chegaram centenas de trabalhos. E todo mundo pensava: "Bom, quem vai aparecer mais é a Emília". Enfim, chegaram muitos trabalhos - nas redações, às vezes, sentia-se a mão de professoras, de pais, não era tão espontâneo. Mas os desenhos, de crianças de 6 ou 7 anos, eram bem espontâneos, bem infantis. E a Emília realmente ganhou um honroso segundo lugar. Mas sabe o que apareceu mais? A mão do Júlio tirando o livro da estante. Não era a cara, mas a mão tirando o livro da estante. Ele aparecia todo de gravata e a manga da camisa branca com abotoadura.

O que se vendeu de Monteiro Lobato naqueles anos foi uma coisa incrível! E nós não ganhávamos nada com isso. Só prestígio. E era esse resultado que esperávamos. Queríamos promover leitura, promover o livro, e funcionou. 
Mas, um belo dia, alguém quis dar palpite e o Júlio disse: "Chega. Não vou mais. Não brinco mais". E, olha, ele saiu no dia seguinte, como havia dito, e abriu novamente o consultório que estava fechado há dez anos. Eu fiquei mais um ano até terminar o contrato, porque a emissora tinha compromissos com os patrocinadores e não podia interromper o programa. Ele, entretanto, como apresentador e diretor, saiu... De um dia para o outro. Eu continuei como roteirista escrevendo para o Teatro da Juventude, por um ano. O programa continuou com o espírito dele, o jeito dele, com a mesma equipe. Nós tínhamos um grupo de teatro muito bom, muito afiado, quase todos amadores ou semiamadores. Era uma turma que não tirou um dia de férias em anos. Amadores, do verbo amar... paixão.

Fizemos nosso teatro por doze anos e depois mais um ano na TV Bandeirantes. Aí o Júlio ficou doente, teve problemas cardíacos, colocou ponte de safena. Mas, depois, a TV Bandeirantes nos convidou: "Nós queremos fazer o Sítio do Pica-pau Amarelo". O programa foi gravado em videoteipe, em branco e preto, uma vez por semana, no horário nobre, em 1967.

\section{MONTEIRO LOBATO E TCHEKOV}

Nós conhecemos o Monteiro Lobato pessoalmente. Ele nos procurou de uma forma muito engraçada, antes da televisão que ele não chegou a ver, pois morreu antes - esse encontro se deu uns cinco anos antes de Monteiro Lobato morrer. Antes também do teatro, antes de tudo, quando não éramos nem um pouco conhecidos. O Júlio era um jovem médico e eu, uma jovem dona de casa com filhos pequenos. Uma noite nós estávamos, o Júlio e eu, em casa, depois do jantar, e tocou o telefone. Atendi e uma voz meio seca perguntou: “Aí é a casa do Júlio Gouveia?". Eu disse: "É. Quem quer falar com ele?”. "Aqui é o Monteiro Lobato", respondeu. Eu falei: "É mesmo, e aqui é o rei Jorge". Era realmente o Monteiro Lobato e eu, simplesmente, achei que era trote. Ele riu e disse: "É o Monteiro Lobato mesmo. Eu li um artigo do Júlio Gouveia na revista 'Literatura e Arte', uma revista onde o Júlio escreveu um artigo como homem da cultura, admirador". Pois é, escreveu um artigo sobre a literatura infantil de Monteiro Lobato, que caiu na mão do dito cujo; ele leu, gostou e disse: "Eu quero conhecer esse Júlio. Posso ir aí hoje à noite?”. Desse jeito!

E chegou às 9 horas. O Júlio abriu a porta para ele, que disse assim: "Na tua idade, eu tinha a tua cara". Não era nem a mesma cara, mas o mesmo tipo. Eram parecidos: sobrancelhas grandes, olhos iguais. Quando nós o conhecemos, ele já não era nenhum mocinho. Morreu alguns anos depois, antes de nós fazermos teatro, antes da televisão. Ele nem ficou sabendo que adaptaríamos seus textos para a televisão. Quem nos cedeu os direitos foi a viúva.

O teatro é uma arte muito importante, porque tem relação direta com o público. É muito forte quando é bem-feito. O Júlio fez um trabalho, uma tese sobre teatro infantil - "o teatro como educação na formação da criança" -, que ele apresentou no $1^{\circ}$ Congresso Brasileiro de Teatro no Rio de Janeiro. 
Estavam presentes todos os grandes diretores, todos os autores, atores, e havia uma enorme agenda, mas teatro para crianças não estava incluído, não era pauta. Aí o Júlio escreveu um ensaio, se mandou para lá e disse: "Ó, vocês esqueceram uma coisa importante". E foi um sucesso, publicaram nos anais e publicaram no livro!

Nós sempre achamos que teatro é coisa de criança também. O bom teatro é para qualquer idade, sem essa bobagem de que criança não entra. As escolas levavam as crianças ao teatro, sem a preocupação de entenda isso ou aquilo. Entenda quando puder... irá entender mais tarde. Quando cheguei ao Brasil, com 10 anos, eu já tinha visto balé, ópera, opereta, teatro de declamação, de tudo... e tudo marca para sempre. Teatro é muito forte.

Fui uma amadora, do verbo amar, uma pioneira e uma profissional do teatro. Mas eu não procurei nada. Tudo me achou. Eu fui achada. Eu comecei como tradutora e foi uma editora que me convidou, por meio do Edgar Cavalheiro, biógrafo de Monteiro Lobato e editor da Companhia Editora Nacional, que dirigia uma série de contos do mundo inteiro. Estávamos numa reunião na minha casa, e aí ele olhou para mim e disse: "Eu preciso de um conto, da tradução de um conto russo, de Tchekov, 'A Mulher do Farmacêutico'. A Tatiana é o homem para fazer isso". "Homem?! Eu?!”, eu disse: "Homem é a sua vovozinha”.

Quando saímos da televisão, quando acabou o contrato, fui convidada pela Comissão Estadual de Teatro para criar um setor infanto-juvenil que não existia. Eu fui para lá e inventei uma revista, Teatro da Juventude, publicada durante anos e depois ressuscitada pelo Marcos Mendonça com peças, teatro e informações sobre teatro para crianças, jovens e amadores. Foi um trabalho importante também. Durante quatro gestões eu fiquei nessa função... mudava o governo, todo mundo saía e eu permanecia, por que quem ia fazer aquela revista? Só eu sabia fazer, então eu acabava ficando.

Depois da quarta gestão eu saí. Em 1972, fui convidada pela Folha de S. Paulo para fazer duas colunas por semana - uma de literatura e outra de teatro para crianças e jovens. Era uma espécie de crítica, um comentário opinativo que eles chamavam de crítica. Enfim, eu falava do que gostava, do que não gostava; indicava o que eu achava bom. Um dia, alguém me perguntou: "Que raio de crítica é você, que gosta de tudo?". Eu disse: "Eu não gosto de tudo, é que eu só falo do que gosto. Não vou perder meu tempo e meu pouco espaço para ficar pichando alguma coisa que não vale a pena; eu quero dar indicações para os pais, para os professores, para as crianças”. Era esse tipo de crítica.

Fiquei três anos lá, mas um dia cortaram trechos de uma coluna, distorcendo o que escrevi. Aí eu disse: "Ah, eu não brinco mais. Não, assim eu não quero. Tchau”. Logo em seguida fui convidada pelo Estadão para o mesmo trabalho: crítica de teatro no Caderno 2. Depois fui para o Jornal da Tarde. Em 1985, telefonaram-me da Editora Ática, perguntando se eu queria escrever histórias para criança. Eu nunca havia publicado um livro, mas tinha muitas histórias para contar. Mandei quatro contos de uma só vez. Assim começou a carreira de escritora que prossegue até hoje, pois continuo aqui escrevendo à mão. 
Todas essas atividades e passagens, do teatro para a televisão, da televisão para o jornal, do jornal para os livros, constituem hoje o legado de uma pioneira e, como sempre, de uma amadora, amadora... do verbo amar.

Resumo: Neste depoimento, Tatiana Belinky reflete sobre como a infância promoveu seus primeiros contatos com o teatro e a literatura, relacionamento que se desenvolveu afetiva e profissionalmente durante toda sua história de vida. O trabalho de adaptação para teatro e televisão progrediu principalmente no campo da literatura que, por sua vez, sempre dialoga com peças extraídas do folclore, da Bíblia, da literatura mundial. Boa literatura, selecionada com critério. Livros pequenos de tamanho, mas não são livrinhos. Combinam a dimensão do maravilhoso à dimensão política. Afinal, são portadores de mensagens que precisam ser entendidas e interpretadas. Em um conto de fadas, por exemplo, interagem oprimidos e opressores, lutam pobres contra ricos. São inúmeras experiências que aprofundaram e refinaram as percepções e a comunicação de Tatiana Belinky com um universo mágico, rico e criativo.

Palavras-chave: criação teatral, criação literária, educação, televisão, minissérie.
Abstract: In this testimony, Tatiana Belinky reflects on how childhood has promoted her first contacts with theater and literature, relationship that was developed affective and professionally along her life history. The work of adapting for theater and television was developed mainly in the field of literature that, by its side, always dialogues with plays extracted from the folklore, the Bible, the world literature. Good literature, judiciously selected. Books small in size, but not small books. They harmonize with the dimension of the marvelous and the political dimension. After all, they are bearers of messages that need to be understood and interpreted. In a fairy tale, for example, oppressed and oppressors interact, poors fight with the riches. Several were the experiences that deepened and refined with a magic, rich and creative universe Tatiana Belinky's perceptions and communication.

Keywords: theatrical creation, literary creation, education, television, miniseries. 